\title{
The "Pulse Time Index of Norm" highly correlates with the left ventricular mass index in patients with arterial hypertension
}

This article was published in the following Dove Press journal:

Vascular Health and Risk Management

19 March 2014

Number of times this article has been viewed

\author{
Igor N Posokhov' \\ Natalya N Kulikova ${ }^{2}$ \\ Irina $\vee$ Starchenkova ${ }^{2}$ \\ Elena A Grigoricheva ${ }^{3}$ \\ Vitaly $V$ Evdokimov ${ }^{3}$ \\ Artemy V Orlov ${ }^{4}$ \\ Anatoly N Rogoza ${ }^{5}$ \\ On behalf of The BPLab- \\ Vasotens Registry \\ Collaborators \\ 'Hemodynamic Laboratory Ltd, \\ Nizhny Novgorod, Russia; ${ }^{2} 3$ rd \\ Republican Hospital, Saransk, Russia; \\ ${ }^{3}$ Chelyabinsk State Medical Academy, \\ Chelyabinsk, Russia; ${ }^{4}$ National \\ Research Nuclear University MEPhl, \\ Moscow, Russia; ${ }^{5}$ Cardiology Research \\ Center, Moscow, Russia
}

Correspondence: Igor N Posokhov PO Box 69, Hemodynamic Laboratory 603009 , Nizhny Novgorod, Russia

$\mathrm{Tel}+79159396222$

$\mathrm{Fax}+79138259111$

Email posokhov@24h-monitoring.com
Background: Arterial stiffness, as measured by the pulse wave velocity (PWV), is recommended for routine use in clinical practice as an important parameter for the evaluation of cardiovascular risk. ${ }^{1}$ New 24-hour monitors (eg, with Vasotens ${ }^{\circledR}$ technology; Petr Telegin Company, Nizhny Novgorod, Russian Federation) provide single PWV measurements as well as several PWV measurements over a period of 24 hours. $^{2}$ Such 24 -hour pulse wave analysis led to the development of the novel Pulse Time Index of Norm (PTIN), which is defined as the percentage of a 24-hour period during which the PWV does not exceed the $10 \mathrm{~m} /$ second PWV threshold. The aim of this study is to test the new PTIN for correlation with the left ventricular mass index (LVMI).

Methods: Oscillometrically generated waveform files $(n=137)$ used for clinical research studies were reanalyzed using the new 2013 version of the Vasotens technology program, which enables PTIN calculations.

Results: A good correlation $(r=-0.72)$ between the PTIN and the LVMI was shown, which was significantly above the blood pressure load $(r=0.41)$.

Conclusion: The PTIN generated by the Vasotens technology can be recommended as an indicator of end organ damage via hypertension.

Keywords: pulse wave velocity, ambulatory, 24-hour, monitoring, PTIN, arterial stiffness, LVMI

\section{Introduction}

Arterial stiffness, as measured by the pulse wave velocity (PWV), is recommended for routine use in clinical practice as an important "vascular" index for the evaluation of cardiovascular risk. ${ }^{1}$ The PWV relates the capability of an artery to expand and contract under the influence of blood pressure (BP) changes. The PWV and other stiffness indices are independent predictors of cardiovascular morbidity and mortality in hypertensive patients, in elderly populations, in patients with end-stage renal disease, and in patients with type 2 diabetes. ${ }^{1}$

A novel cuff-based method, such as Vasotens ${ }^{\circledR}$ (Petr Telegin Company, Nizhny Novgorod, Russian Federation), determines the PWV from oscillometric measurements of the brachial artery waveform. This system for PWV measurements integrated into an ambulatory BP monitoring (ABPM) system provides single PWV measurements as well as several PWV measurements over a period of 24 hours. Such 24-hour pulse wave analysis has led to the development of the novel Pulse Time Index of Norm (PTIN), which is defined as the percentage of a 24-hour period during which the PWV does not exceed the threshold of the PWV of $10 \mathrm{~m} /$ second. $^{2,3}$ 
This cutoff value is well known as a threshold for hypertensive target organ damage. ${ }^{1,4,5}$ The PTIN calculation is similar to the principle of the BP load calculation. Several studies have shown that the mean 24-hour BP did not correlate with the left ventricular mass index (LVMI); however, an increased BP load was associated with a higher LVMI. ${ }^{6,7}$

Does the PTIN provide additional information about cardiovascular risk? Recently registries have been established in European countries to assess the impact of ABPM on hypertension management and related outcomes. ABPM registries are more commonly focused on patients with documented or possible hypertension who would benefit from ABPM. The BPLab-Vasotens registry that was established this year is the project of dozens of small groups aimed at joint solutions for various scientific problems. One of the challenges is research into new ABPM "vascular" indices.

To study the association of the PTIN with the LVMI, we used the ability to work with archives of the BPLabVasotens registry, which is provided by a unique feature of the Vasotens technology. This technology processes the oscillometrically generated waveform files that are received, digitized, and stored into the computer memory by the BPLab $^{\circledR}$ (Petr Telegin Company) software for ABPM. The data processing can be performed during the analysis or at any time after the ABPM study.

\section{Methods}

\section{Baseline characteristics}

Overall, 137 oscillometrically generated waveform files that had previously been used in clinical research studies with ABPM were reanalyzed using the new 2013 version of the Vasotens technology program. The detailed baseline characteristics of the patients whose waveform files were used are shown in Table 1. These were patients with arterial hypertension; athletes and patients with a body mass index greater than $27.5 \mathrm{~kg} / \mathrm{m}^{2}$ were excluded from the study.

All of the studies in which the data were reanalyzed were authorized by the local ethics commissions. All of the enrolled patients provided written informed consent.

\section{Vasotens}

The Vasotens technology is an innovative method for pulse wave analysis based on oscillometric BP measurement by the BPLab device (Petr Telegin Company). ${ }^{89}$ The method of PTIN calculation consists of assessing the PWV. The PWV estimation method used for this parameter is based on identification of the reflected wave on the pulse curve at the arteria brachialis, taking into account the delay of the
Table I The baseline characteristics of the examined patients, $\mathrm{n}=137$

\begin{tabular}{ll}
\hline Characteristic & Value \\
\hline Male, $\mathrm{n}(\%)$ & $83(6 \mathrm{I})$ \\
Age, mean (SD) years & $46(18)$ \\
Height, mean (SD) cm & $168(7)$ \\
Weight, mean (SD) kg & $83(17)$ \\
SBP, mean (SD) mmHg & $144(23)$ \\
DBP, mean (SD) mmHg & $82(13)$ \\
Heart rate, mean (SD) bpm & $73(14)$ \\
Hypertension, $\mathrm{n}(\%)$ & $137(100)$ \\
Duration of hypertension history, mean (SD) years & $6(3)$ \\
Medication: thiazide diuretics, $\mathrm{n}(\%)$ & $80(58)$ \\
Medication: angiotensin-receptor blockers, $\mathrm{n}(\%)$ & $9 \mathrm{I}(66)$ \\
Medication: beta-blockers, $\mathrm{n}(\%)$ & $60(44)$ \\
Medication: other, $\mathrm{n}$ (\%) & $5 \mathrm{I}(37)$ \\
Drug combinations, $\mathrm{n}(\%)$ & $128(93)$ \\
Previous Ml or stroke, $\mathrm{n}(\%)$ & $26(19)$ \\
LVH, $\mathrm{n}(\%)$ & $75(55)$ \\
Renal disease, $\mathrm{n}(\%)$ & $4(3)$ \\
\hline
\end{tabular}

Abbreviations: DBP, diastolic blood pressure; LVH, left ventricular hypertrophy; MI, myocardial infarction; SBP, systolic blood pressure; SD, standard deviation.

reflected wave relative to the direct wave. The transit time of both the direct wave and the reflected wave is equal to double the length of the aortic trunk. A more detailed description of the method was published in a recent review. ${ }^{2}$

Recordings are made in the ambulatory (ie, 24-hour) measurement mode using a conventional BP cuff for adults. During the BP measurement, the pressure waveforms in the cuff are registered while performing a step-by-step deflation. The separation and timing of the forward and reflected pulse waves are performed by a Vasotens mathematical algorithm. The distance for the PWV equation used in this technology was measured in accordance with the manufacturer's instructions. Quality control is based on visual assessment of the curves in the Vasotens clinical report screen. The PTIN calculation is illustrated in Figure 1.

\section{BP load}

We found it appropriate to use the identical BPLab device to evaluate the BP load because the hardware has an A/A class of accuracy for BP measurement. ${ }^{10}$ The BP load is defined as the percentage of a 24-hour period in which either the systolic BP exceeds the cutoff values of $135 \mathrm{mmHg}$ during the day and $120 \mathrm{mmHg}$ at night or the diastolic BP exceeds the cutoff values of $85 \mathrm{mmHg}$ during the day and $70 \mathrm{mmHg}$ during the night.

\section{LVMI}

The LVMI was determined for 137 hypertensive patients using two-dimensional guided M-mode echocardiography performed 


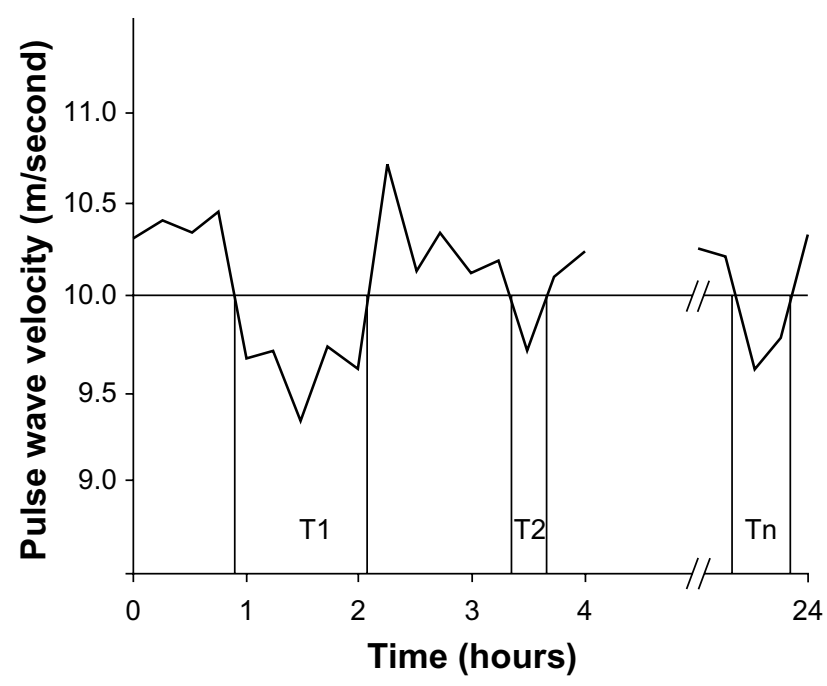

Figure I The PTIN calculation principle.

Notes: TI, T2 and Tn are the periods in which the PWV does not exceed the cutoff value of $10 \mathrm{~m} /$ second. PTIN, $\%=(T I+T 2+\ldots+T n) / T m \times 100$, where $T m$ is the entire period of monitoring, Pulse Time Index of Norm. ${ }^{2,22}$

Abbreviations: PTIN, Pulse Time Index of Norm; PWV, pulse wave velocity.

with standard methods using an ultrasound system (Logiq 9 and Logiq 7 Ultrasound Machine; General Electric, Fairfield, CT, USA) with a 2.25-MHz transducer. The left ventricular internal dimension (LVID), the interventricular septal thickness (IVST), and the posterior wall thickness (PWT) were measured during the end diastole period, in accordance with the American Society of Echocardiography (ASE) recommendations. ${ }^{11}$ The left ventricular (LV) systolic and diastolic diameters and the IVST and the PWT were measured during the end diastole period, which was defined by the beginning of the qRs-complex. The left ventricular mass (LVM) was calculated using the following corrected ASE formula by Devereux et al: ${ }^{12}$

$$
\begin{aligned}
\mathrm{LVM}= & 1.04 \times\left[\{\mathrm{LVID}+\mathrm{PWT}+\mathrm{IVST}\}^{3}-\mathrm{LVID}^{3}\right] \\
& \times 0.8+0.6
\end{aligned}
$$

where LVID, left ventricular PWT, and IVST are measured in centimeters. The LVM was indexed by the body surface area $\left(\mathrm{LVM} / \mathrm{BSA}, \mathrm{g} / \mathrm{m}^{2}\right)$, which was calculated using the Dubois formula, and by height ${ }^{2.7}\left(\mathrm{LVM} /\right.$ height $\left.^{2.7}, \mathrm{~g} / \mathrm{m}^{2.7}\right)$, as recommended by de Simone et al. ${ }^{13}$ We set the cutoff values for left ventricular hypertrophy (LVH) as LVM/BSA $\geq 116$ $\mathrm{g} / \mathrm{m}^{2}$ in males and $\geq 96 \mathrm{~g} / \mathrm{m}^{2}$ in females; the cutoff value for the LVM/height ${ }^{2.7}$ was $\geq 49 \mathrm{~g} / \mathrm{m}^{2.7}$ in males and $\geq 45 \mathrm{~g} / \mathrm{m}^{2.7}$ in females. ${ }^{14}$

\section{Statistics}

We used BPStat (Petr Telegin Company) software, version 05.00.04 for the automatic tabulation of the indices of every measured waveform. Statistica (StatSoft Inc., Tulsa, OK, USA) software for Windows 8.0 was used for the analysis.

\section{Results}

The 137 hypertensive patient ABPM waveform files were reanalyzed. First, it should be noted that the distribution of PTIN within this group could not be considered normal. The distribution is shown in Figure 2. Therefore, subsequent statistical analyses were performed with nonparametric tests that do not require the normality assumption that is usually used in parametric tests. For instance, to test for the correlation between the variables, we used Spearman's $r$ instead of the classical Pearson's $r$ coefficient.

Thus, correlation analysis with the LVM/ height ${ }^{2.7}$ showed $r=-0.72(P<0.0001)$ for the PTIN (Figure 3A), $r=0.41$ $(P<0.001)$ for the systolic BP load (Figure 3B), and $r=0.47$ $(P<0.001)$ for the diastolic BP load (Figure 3C). The correlation between LVMI and PTIN was markedly higher.

Other correlations obtained in the study are presented in Table 2. It should be noted that the PTIN has more significant correlation coefficients with LVMI than the average PWV per day or its variability.

Important results were also obtained when PTIN was compared in patients with and without LVH. Figure 4 shows PTIN in 24-hour awake and asleep periods in these patients. As we can see, the boundaries of the PTIN percentile limits for the "asleep" period in these subgroups do not intersect. There are high significance levels (Yates corrected $\chi^{2}=34.2$, $P<0.001)$ if we construct a two-by-two table for awake and asleep periods in the subgroups listed above.

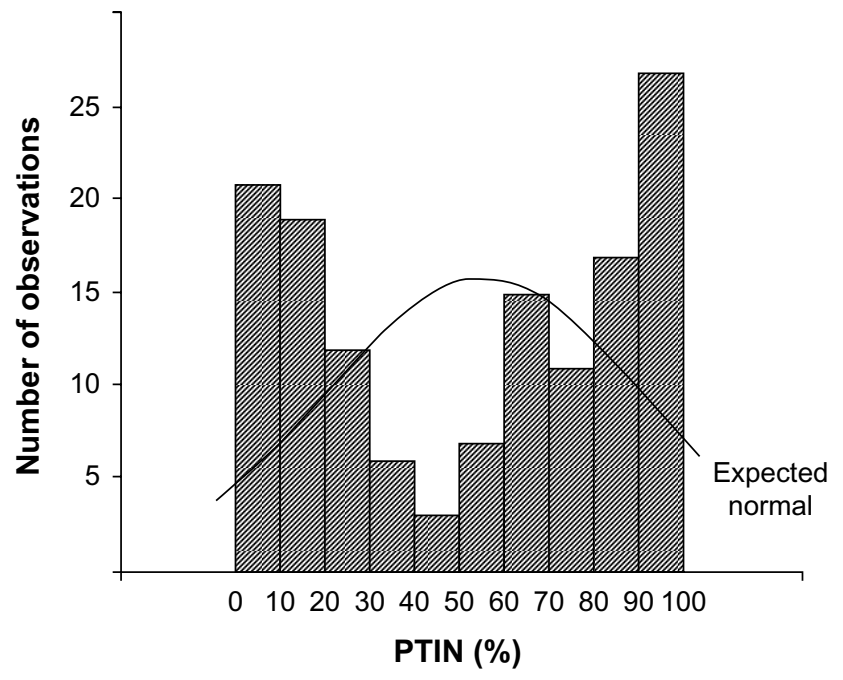

Figure 2 Histogram of PTIN distribution - observed frequencies and expected normal curve.

Note: Pulse Time Index of Norm. ${ }^{2,22}$

Abbreviation: PTIN, Pulse Time Index of Norm. 


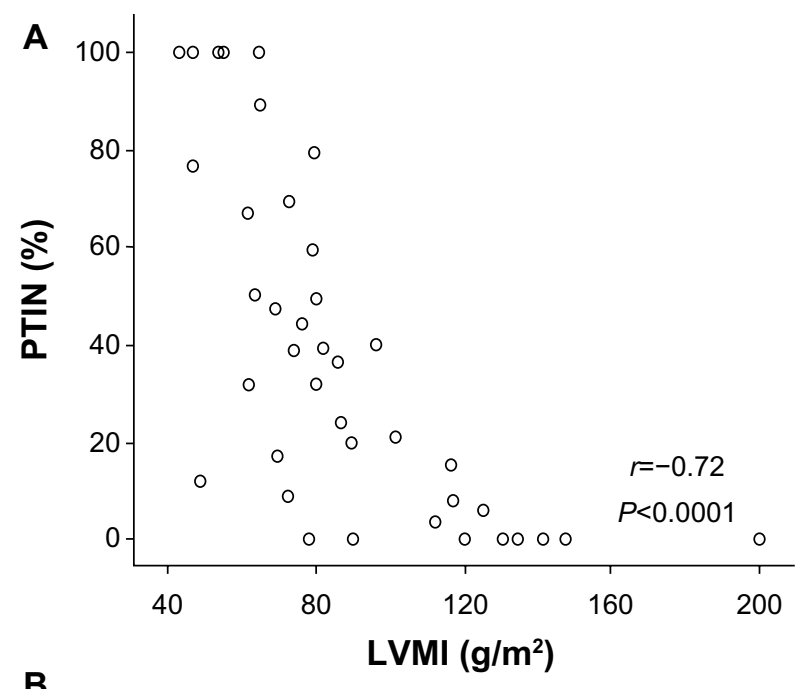

в
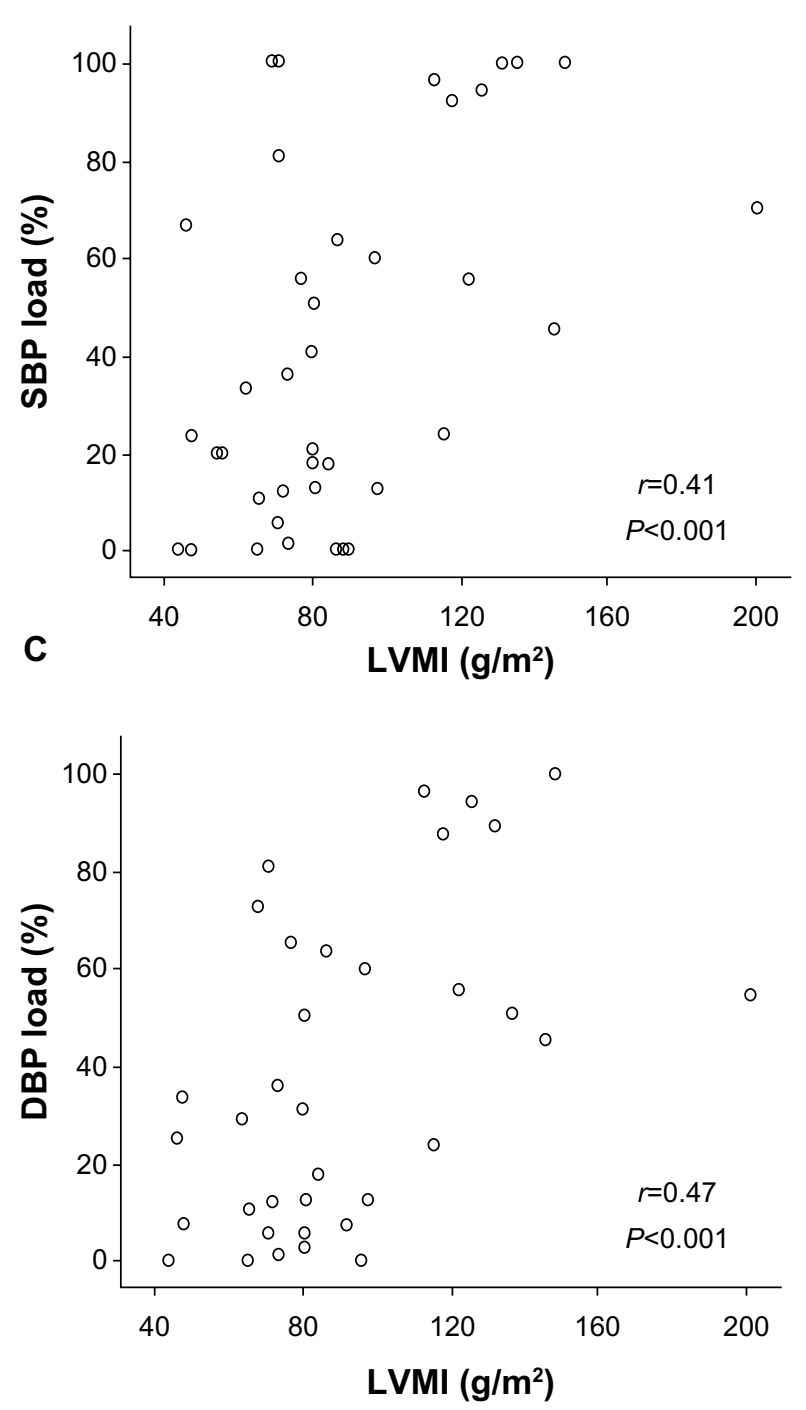

Figure 3 Correlation between the LVMI ( $\left(\mathrm{g} / \mathrm{m}^{2}\right)$ and: (A) the PTIN (\%), (B) the SBP load (\%), and (C) the DBP load (\%).

Notes: Pulse Time Index of Norm. ${ }^{2,22}$

Abbreviations: DBP, diastolic blood pressure; SBP, systolic blood pressure; LVMI, left ventricular mass index; PTIN, Pulse Time Index of Norm.
Table 2 The correlations between the echocardiographic data and the BPLab Vasotens ${ }^{\circledR}$ (Petr Telegin Company, Nizhny Novgorod, Russian Federation) indices

\begin{tabular}{|c|c|c|c|c|}
\hline & \multicolumn{2}{|c|}{ LVM/height $^{2.7}$} & \multicolumn{2}{|c|}{ LVM/BSA } \\
\hline & $r$ & $P$-value & $r$ & $P$-value \\
\hline PTIN & -0.72 & 0.0001 & -0.67 & 0.0001 \\
\hline Mean 24-hour PWV & 0.32 & 0.01 & 0.32 & 0.01 \\
\hline Variability of PWV & 0.12 & $>0.05$ & 0.12 & $>0.05$ \\
\hline SBP load & 0.41 & 0.001 & 0.37 & 0.01 \\
\hline DBP load & 0.47 & 0.001 & 0.37 & 0.01 \\
\hline Mean SBP & 0.14 & $>0.05$ & 0.15 & $>0.05$ \\
\hline Mean DBP & 0.29 & $>0.05$ & 0.19 & $>0.05$ \\
\hline
\end{tabular}

Note: Pulse Time Index of Norm. ${ }^{2,22}$

Abbreviations: BSA, body surface area; DBP, diastolic blood pressure; LVM, left ventricular mass; PTIN, Pulse Time Index of Norm; PWV, pulse wave velocity; SBP, systolic blood pressure.

\section{Discussion}

LVH is the most commonly assessed target organ effect of hypertension, and it is associated with a significantly increased cardiac risk in adults. ${ }^{15}$ Several studies have shown that LVH, as with other markers of target organ damage, correlates with ambulatory BP more closely than with office BP. ${ }^{16,17}$ A number of additional indices that might be derived from the ABPM recordings have been investigated; however, their added predictive value is not clear, and they should be regarded as experimental. ${ }^{1}$ Some studies support the usefulness of circadian BP rhythm (a dipping pattern, morning BP) in predicting organ damage..$^{18,19}$ Other studies show the usefulness of the BP load in predicting organ damage. ${ }^{6,7,20}$ In this present study, we obtained a similar correlation between the BP load and

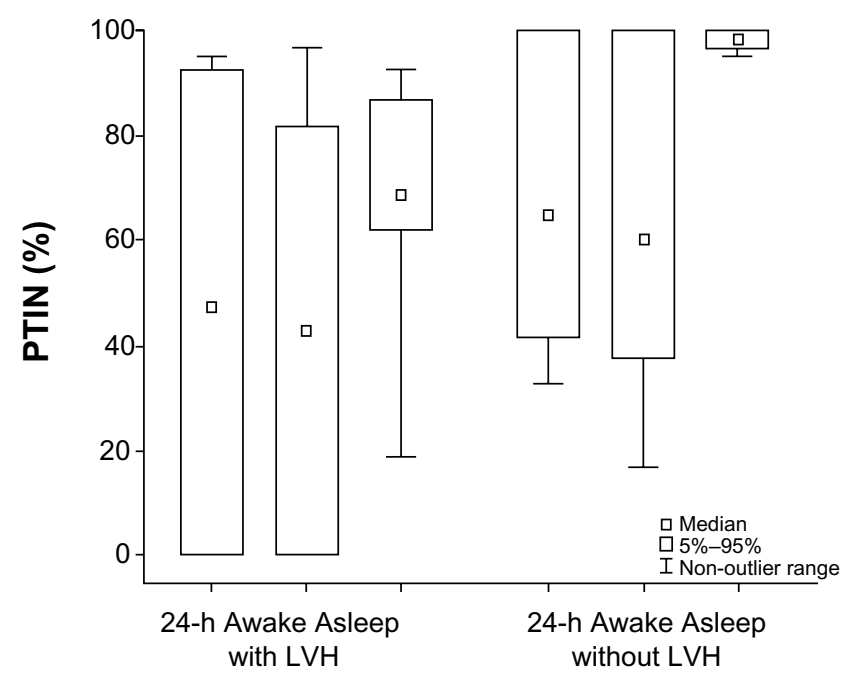

Figure 4 Medians, limits of the fifth and 95th percentiles and non-outlier range of PTIN according to 24-hour awake and asleep periods in patients with and without LVH. Notes: Pulse Time Index of Norm.,22

Abbreviations: LVH, left ventricular hypertrophy; PTIN, Pulse Time Index of Norm; h, hour. 
the LVMI. One study has also shown an association of the ambulatory arterial stiffness index with the LVMI. ${ }^{21}$

Considering the above studies, our results from the PTIN study are very important. The correlation with the LVMI appears to be the highest among the correlations in similar studies of additional ABPM indexes. A difference can be seen in the correlations of the mean PWV with the LVMI $(r=0.32)$ and of the PTIN with the LVMI ( $r=-0.72)$. In a comparison of recordings with similar average PWV levels, the differences in the PTIN can be largely explained by the differences in the PWV variability. Finally, the correlation of the PTIN of the "asleep" period with the presence of LVH is quite significant.

Our study has some limitations, which might have affected the results. Because the distribution of the PTIN is non-normal, the adjustment of the correlation between PTIN and LVM using analysis of variance or analysis of covariance is not possible. Perhaps the correlation differs across age groups or in patients with varying clinical parameters.

It is evident that only an event-based longitudinal study can provide an indisputable answer to the question of the clinical relevance of additional ABPM indices. Our previous work on the reliability of PTIN shows its good repeatability. ${ }^{22}$ Thus, given the above results, we believe that the PTIN especially during the "asleep" period should also be considered in forthcoming research.

\section{Conclusion}

The PTIN generated by the Vasotens technology can be recommended as an indicator of end organ damage resulting from hypertension.

\section{Acknowledgments}

Members of the BPLab-Vasotens Registry Group are as follows: Hemodynamic Laboratory Ltd, Nizhny Novgorod, Russia (Igor N Posokhov and Georgy D Nesterov); Universitätsklinikum Schleswig-Holstein, Campus Lübeck, Med. Klinik II, Lübeck, Germany (Johannes Baulmann); Cardiology Research and Production Complex, Moscow, Russia (Anatoly N Rogoza); People's Friendship University of Russia, Medical Faculty, Moscow, Russia (Zhanna D Kobalava and Yulia V Kotovskaya); Almazov Federal Heart, Blood and Endocrinology Centre, Saint-Petersburg, Russia (Aleksandra O Konradi, Eugeny V Shlyakhto, and Oleg V Mamontov); Petrozavodsk State University, Petrozavodsk, Russia (Viktoria A Korneva and Tatyana Y Kuznetsova); 3rd Republican Hospital, Saransk, Russia (Natalya N Kulikova and Irina V Starchenkova); Department 65 Competitive System Analysis, National Research Nuclear University MEPhI, Moscow, Russia (Artemy V Orlov); Chelyabinsk State Medical Academy, Chelyabinsk, Russia (Elena A Grigoricheva and Vitaly V Evdokimov); and the hospital within the Russian Railroad Network, Chita, Russia (Evgeniya N Bryantseva, Vitaliy S Barkan, Vladimir V Gorbunov, and Sergey A Alekseev).

\section{Disclosure}

$\mathrm{BPLab}^{\circledR}$ ABPM systems allowed NNK and EAG to participate in a previous scientific competition (2008-2012) organized by the manufacturer, Petr Telegin Company, in the Russian Federation. The BPStat ${ }^{\circledR}$ software was provided to INP and AVO by the manufacturer (Petr Telegin Company). The other authors report no conflicts of interest in this work.

\section{References}

1. Mancia G, Fagard R, Narkiewicz K, et al. 2013 ESH/ESC Guidelines for the management of arterial hypertension: the Task Force for the management of arterial hypertension of the European Society of Hypertension (ESH) and of the European Society of Cardiology (ESC). J Hypertens. 2013;31(7):1281-1357.

2. Posokhov IN. Pulse wave velocity 24-hour monitoring with one-site measurements by oscillometry. Med Devices (Auckl). 2013;6:11-15.

3. Minyukhina IE, Lipatov KS, Posokhov IN. Analysis of 24-hour pulse wave velocity in patients with renal transplantation. Int $J$ Nephrol Renovasc Dis. 2013;6:125-129.

4. Van Bortel LM, Laurent S, Boutouyrie P, et al. Expert consensus document on the measurement of aortic stiffness in daily practice using carotid-femoral pulse wave velocity. J Hypertens. 2012;30(3): 445-448.

5. Baulmann J, Nürnberger J, Slany J, et al. [Arterial stiffness and pulse wave analysis]. Dtsch Med Wochenschr. 2010;135 Suppl:4-14. German.

6. Jang JS, Kwon SK, Kim HY. Comparison of blood pressure control and left ventricular hypertrophy in patients on continuous ambulatory peritoneal dialysis (CAPD) and automated peritoneal dialysis (APD). Electrolyte Blood Press. 2011;9(1):16-22.

7. Falqui V, Viazzi F, Leoncini G, et al. Blood pressure load, vascular permeability and target organ damage in primary hypertension. J Nephrol. 2007;20 Suppl 12:S63-S67.

8. Rogoza AN, Kuznetsov AA. Central aortic blood pressure and augmentation index: comparison between Vasotens ${ }^{\mathbb{B}}$ and SphygmoCor ${ }^{\sqrt{R}}$ technology. Res Rep Clin Cardiol. 2012;3:27-33.

9. Ageenkova OA, Purygina MA. Central aortic blood pressure, augmentation index, and reflected wave transit time: reproducibility and repeatability of data obtained by oscillometry. Vasc Health Risk Manag. 2011;7:649-656.

10. Koudryavtcev SA, Lazarev VM. Validation of the BPLab ${ }^{\circledR} 24$-hour blood pressure monitoring system according to the European standard BS EN 1060-4: 2004 and British Hypertension Society protocol. Medical Devices: evidence and research. 2011;4:193-196.

11. Sahn DJ, DeMaria A, Kisslo J, Weyman A. Recommendations regarding quantitation in M-mode echocardiography: results of a survey of echocardiographic measurements. Circulation. 1978;58(6):1072-1083.

12. Devereux RB, Alonso DR, Lutas EM, et al. Echocardiographic assessment of left ventricular hypertrophy: comparison to necropsy findings. Am J Cardiol. 1986;57:450-458. 
13. de Simone G, Kizer JR, Chinali M, et al; Strong Heart Study Investigators. Normalization for body size and population-attributable risk of left ventricular hypertrophy: the Strong Heart Study. Am J Hypertens. 2005;18(2 Pt 1):191-196.

14. Lang RM, Bierig M, Devereux RB, et al. Recommendations for chamber quantification: a report from the American Society of Echocardiography's Guidelines and Standards Committee and the Chamber Quantification Writing Group, developed in conjunction with the European Association of Echocardiography, a branch of the European Society of Cardiology. J Am Soc Echocardiogr. 2005;18: $1440-1463$

15. Levy D, Garrison RJ, Savage DD, Kannel WB, Castelli WP. Prognostic implications of echocardiographically determined left ventricular mass in the Framingham Heart Study. $N$ Engl J Med. 1990;322(22): $1561-1566$.

16. Gaborieau V, Delarche N, Gosse P. Ambulatory blood pressure monitoring vs self-measurement of blood pressure at home: correlation with target organ damage. J Hypertens. 2008;26:1919-1927.
17. Bliziotis IA, Destounis A, Stergiou GS. Home vs ambulatory and office blood pressure in predicting target organ damage in hypertension: a systematic review and meta-analysis. J Hypertens. 2012;30:1289-1299.

18. Hoshide Y, Umeda Y, Hashimoto T, et al. Associations between nondipping of nocturnal blood pressure decrease and cardiovascular target organ damage in strictly selected community-dwelling normotensives. Am J Hypertens. 2003;16:434-438.

19. Soylu A, Yazici M, Duzenli MA, Tokac M, Ozdemir K, Gok H. Relation between abnormalities in circadian blood pressure rhythm and target organ damage in normotensives. Circ J. 2009;73(5):899-904.

20. White WB. Blood pressure load and target organ effects in patients with essential hypertension. J Hypertens. 1991;9:S39-S41.

21. Lee HT, Lim YH, Kim BK, et al. The relationship between ambulatory arterial stiffness index and blood pressure variability in hypertensive patients. Korean Circ J. 2011;41(5):235-240.

22. Posokhov IN, Konradi AO, Shlyakhto EV, Mamontov OV, Orlov AV, Rogoza AN. Day-to-day repeatability of the 'Pulse Time Index of Norm'. Med Devices (Auckl). 2014;7:29-33.
Vascular Health and Risk Management

\section{Publish your work in this journal}

Vascular Health and Risk Management is an international, peerreviewed journal of therapeutics and risk management, focusing on concise rapid reporting of clinical studies on the processes involved in the maintenance of vascular health; the monitoring, prevention and treatment of vascular disease and its sequelae; and the involvement of

\section{Dovepress}

metabolic disorders, particularly diabetes. This journal is indexed on PubMed Central and MedLine. The manuscript management system is completely online and includes a very quick and fair peer-review system, which is all easy to use. Visit http://www.dovepress.com/ testimonials.php to read real quotes from published authors. 